\title{
Methods for resolving the Braess paradox in the presence of autonomous vehicles
}

\author{
E. A. Belkina ${ }^{1, a}$, E. A. Zhestov ${ }^{1, b}$, A. V. Shestakov ${ }^{2, c}$ \\ ${ }^{1}$ Moscow Institute of Physics and Technology (State University), \\ 9 Institutskiy per., Dolgoprudny, Moscow Region, 141701, Russia \\ ${ }^{2}$ Lomonosov Moscow State University, \\ GSP-1, Leninskie Gory, Moscow, 119991, Russia \\ E-mail: ${ }^{a}$ elisablkn@gmail.com, ${ }^{\mathrm{b}}$ zhestov.ea@phystech.edu, ${ }^{\mathrm{c}}$ art.shestakov.cmc@gmail.com
}

Received 14.09.2020.

Accepted for publication 22.11.2020.

\begin{abstract}
Roads are a shared resource which can be used either by drivers and autonomous vehicles. Since the total number of vehicles increases annually, each considered vehicle spends more time in traffic jams, and thus the total travel time prolongs. The main purpose while planning the road system is to reduce the time spent on traveling. The optimization of transportation networks is a current goal, thus the formation of traffic flows by creating certain ligaments of the roads is of high importance. The Braess paradox states the existence of a network where the construction of a new edge leads to the increase of traveling time. The objective of this paper is to propose various solutions to the Braess paradox in the presence of autonomous vehicles. One of the methods of solving transportation topology problems is to introduce artificial restrictions on traffic. As an example of such restrictions, this article considers designated lanes which are available only for a certain type of vehicles. Designated lanes have their own location in the network and operating conditions. This article observes the most common two-roads traffic situations, analyzes them using analytical and numerical methods and presents the model of optimal traffic flow distribution, which considers different ways of lanes designation on isolated transportation networks. It was found that the modeling of designated lanes eliminates Braess' paradox and optimizes the total traveling time. The solutions were shown on artificial networks and on the real-life example. A modeling algorithm for Braess network was proposed and its correctness was verified using the real-life example.
\end{abstract}

Keywords: Braess paradox, mathematical modeling, autonomous vehicles

Citation: Computer Research and Modeling, 2021, vol. 13, no. 2, pp. 281-294 (Russian).

(c) 2021 Elizaveta A. Belkina, Egor A. Zhestov, Artem V. Shestakov This work is licensed under the Creative Commons Attribution-NoDerivs 3.0 Unported License. To view a copy of this license, visit http://creativecommons.org/licenses/by-nd/3.0/ or send a letter to Creative Commons, PO Box 1866, Mountain View, CA 94042, USA. 
УДК: 519.852 .35

\title{
Методы решения парадокса Браесса на транспортной сети с автономным транспортом
}

\author{
Е. А. Белкина ${ }^{1, a}$, Е. А. Жестов ${ }^{1, b}$, А. В. Шестаков ${ }^{2, c}$ \\ ${ }^{1}$ Московский физико-технический институт (государственный университет), \\ Россия, 141701, Московская область, г. Долгопрудный, пер. Институтский, д. 9 \\ ${ }^{2}$ Московский государственный университет имени М. В. Ломоносова, \\ Россия, 119991, г. Москва, Ленинские горы, ГСП-1 \\ E-mail: ${ }^{\mathrm{a}}$ elisablkn@gmail.com, ${ }^{\mathrm{b}}$ zhestov.ea@phystech.edu, ${ }^{\mathrm{c}}$ art.shestakov.cmc@gmail.com
}

Получено 14.09.2020.

Принято к публикации 22.11.2020.

Дороги - ресурс, который может использоваться как водителями, так и автономными транспортными средствами. Ежегодно количество транспортных средств увеличивается, из-за чего каждое отдельно взятое транспортное средство тратит всё больше времени в пробках, тем самым увеличивая суммарные временные затраты. При планировании новой дороги ключевой задачей становится сокращение времени в пути. Оптимизация транспортных сетей в настоящее время часто происходит с помощью добавления новых связующих дорог между высоконагруженными частями трасс. Парадокс Браесса заключается в том, что построение нового ребра дорожной сети приводит к увеличению времени в пути для каждого транспортного средства в сети. Целью данной статьи является предложение различных разрешений парадокса Браесса при рассмотрении автономных транспортных средств в качестве участников дорожного движения. Один из вариантов топологического решения транспортной задачи - использование искусственных ограничителей трафика. Как пример таких ограничителей статья рассматривает введение выделенных полос, доступных только для определенных видов транспорта. Выделенные полосы занимают особое место в транспортной сети и могут обслуживать поток по-разному. В данной статье рассмотрены наиболее часто встречающиеся случаи распределения трафика на сети из двух дорог, приведены аналитический и численный методы оптимизации модели и представлена модель оптимального распределения трафика, которая рассматривает различные варианты выделения полос на изолированной транспортной сети. В результате проведенных исследований было обнаружено, что введение выделенных полос решает парадокс Браесса и приводит к уменьшению общего времени в пути. Решения приведены как для искусственно смоделированной сети, так и на реальных примерах. В статье представлен алгоритм моделирования трафика на браессовской сети и приведено обоснование его корректности на реальном примере. средства

Ключевые слова: парадокс Браесса, математическое моделирование, автономные транспортные 


\section{Introduction}

The problems of transportation networks have recently become an urgent issue, since the number of vehicles increased and there is an objective of optimal planning of road systems. The problem is particularly acute in large cities with lots of cars and public transport. According to WHO, half of the modern world's population lives in cities. According to the UN forecast, by 2050 , about $85 \%$ of the world's population will prefer an urban lifestyle [Thorns, 2017]. Since the total number of vehicles increases annually, the vehicle considered spends more time in traffic jams, and thus the total travel time prolongs. The main purpose while planning the route is to reduce the time spent on traveling. Since possible routes require different costs and time depending on the type of the vehicle, this article presents the model of optimal traffic flow distribution. This model considers different ways of lanes designation on isolated transportation networks and proposes an algorithm for implementing optimal traffic flow distribution over the transportation network.

Roads are a shared resource which can be used either by drivers and autonomous vehicles. The optimization of transportation networks is a current goal, thus the formation of traffic flows by creating certain ligaments of the roads is of high importance.

However, some problems occur in planning transportation systems. The main purpose is to reduce travel costs on transport networks. Therefore, it is important to consider and optimize the system as a whole and not by parts. Wardrop showed that the total traveling time on all routes used is not greater than the total traveling time of any vehicle on unused routes, since drivers tend to choose the route according to the total traveling time criterion [Wardrop, 1952]. Hence, the driver would not choose the route with less traffic if the total traveling time is greater than on a route with more traffic. The Nesterov-de Palma model [Nesterov, 2003] is based on the concepts of equilibrium proposed in [Wardrop, 1952]. Each driver tends to choose the most optimal trajectory, no matter what other drivers choose. This principle is similar to Nash equilibrium and is called Wardrop equilibrium [Wardrop, 1952]. However, this equilibrium is not necessarily Pareto-optimal [Wardrop, 1952]. Thus, the search for Wardrop equilibrium can be represented as a game model [Fisk, 1984]. This leads to the occurrence of the so-called Braess paradox on transport networks. This paradox states the existence of a network where the addition of the new edge leads to an increase in traveling time [Braess, 2005]. The search for such inefficient edges is an NP-hard problem [Roughgarden, 2006]. On the other hand, Miltaich indicated that the network of parallel edges is the only network in which Braess' paradox is impossible [Milchtaich, 2006]. Valiant and Roughgarden in 2006 showed that the Braess paradox appearance probability in random graphs with an infinite number of nodes converges to 1 [Valiant, 2010].

One of the methods of solving transportation topology problems is to introduce artificial restrictions on traffic. As an example of such restrictions consider designated lanes which are available only for a certain type of vehicles. Designated lanes have their own location in the network and operating conditions [Kieslingm 2006]. Nevertheless, designating lanes for autonomous vehicles may lead to an increased capacity of roads which are available for all types of vehicles and, as a consequence, to a growth in individual and total costs [Rezende, 2014]. It deals with the Downs Thomson paradox demonstrated in 1962.

\section{Problem Setting}

In general, the real network is represented by a set of roads and road intersections. There are two main different representation methods for urban street networks, called the primal approach and the dual approach. The primal representation is a natural and intuitional approach, which takes just the road segments as edges, and intersections or the ends of roads as vertices for an urban street network. 
We consider a road network as a weighted graph. In what follows, we assume that the travel time cost $t_{i}$ on the road segment $i$ can be represented by the linear function

$$
t_{i}=\tau_{i}+b_{i} n_{i}
$$

where

$\tau_{i}$ is travel time at the highest possible speed and in the absence of other vehicles on the road segment $i$, $b_{i}$ is inversed coefficient of capacity of the road segment $i$. This coefficient shows that the more traffic is on the road, the longer is the travel time for each considered vehicle, and $n_{i}$ is the number of vehicles on the road segment $i$.

Generally, in Beckmann-based traffic models the dependence between the fleet-size and the total delay is not linear. However, the NP-complexity of general problem setting implies the need for heuristics, which can be developed using linear regression methods. In this article, we define two types of vehicles: autonomous vehicles and common ones. As far as the designated lanes are concerned, the travel costs for each of them may differ.

Let $t_{i_{a}}=\tau_{i_{a}}+b_{i_{a}} n_{i_{a}}$ be the travel time of autonomous vehicles, and $t_{i_{c}}=\tau_{i_{c}}+b_{i_{c}} n_{i_{c}}$ be the travel time of common vehicles.

After splitting the fleet of vehicles into autonomous and common ones, we get:

$$
\begin{aligned}
& b_{i_{a}}=\frac{b_{i}}{\lambda_{i}}, \\
& b_{i_{c}}=\frac{b_{i} \chi}{1-\lambda_{i}},
\end{aligned}
$$

where

$\chi>1, \chi$ is the efficiency (inefficiency) coefficient and

$\lambda_{i} \in[0,1]$ is the quotient of the number of designated lanes to the total number of lanes.

The coefficient of efficiency shows the rate of change in the speed of autonomous vehicles from the fleet-size, which depends on the fleet homogeneity [Daganzo, 2002; Kerner, 2006].

Each member of the fleet of common vehicles chooses a path with the minimal travel time cost. It moves towards the user equilibrium in the traffic network. In what follows the total time cost in the network is referred as to $T C$. User equilibrium is not necessary Pareto-optimal. The problem of minimization of $T C$ leads us to the system optimum [Wardrop, 1952; Beckmann, 1955; Valiant, 2010] in the network considered. In this article a part of a road network on which Braess's paradox occurs is considered. As a solution to the paradox the idea of creating designated lanes for certain types of transport (e.g. autonomous vehicles) is proposed.

\section{Analytical solutions}

Consider a simple transportation subnetwork of two parallel roads (Fig. 1). Let

$$
\begin{aligned}
& t_{1_{a}}=\tau_{1}+b_{a} m_{1}, \\
& t_{2_{a}}=\tau_{2}+d_{a} m_{2}, \\
& t_{1_{c}}=\tau_{1}+b_{c} n_{1}, \\
& t_{2_{c}}=\tau_{2}+d_{c} n_{2},
\end{aligned}
$$

where $a$ denotes coefficients of autonomous vehicles and $c$ denotes coefficients of common vehicles and $m_{i}>0$ and $n_{i}>0$ is the total number of vehicles on the road segment $i, i \in\{1,2\}$. 


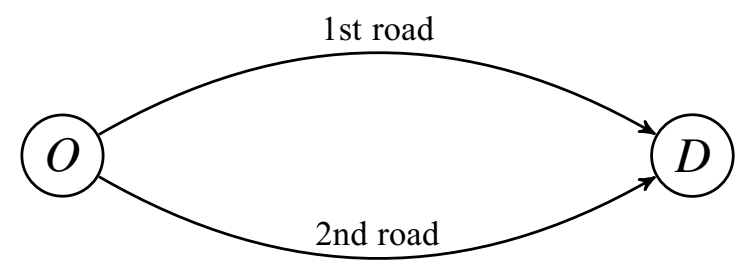

Figure 1. The main example of a two-roads network. $O$ is a source and $D$ is a sink

Let $m_{1}+m_{2}=m>0$ be the total number of autonomous vehicles and $n_{1}+n_{2}=n>0$ be the total number of common vehicles.

We aim to find the user equilibrium under the assumption that there exist no unused roads. This implies that there is a positive number of vehicles on each route $\left(m_{1}+n_{1}>0, m_{2}+n_{2}>0\right)$. According to Wardrop equilibrium, the total traveling time on route 1 is equal to the total traveling time on route 2 , then

$$
\tau_{1}+b_{c} n_{1}=\tau_{2}+d_{c} n_{2}
$$

Hence,

$$
\begin{aligned}
& n_{1}=\frac{\tau_{2}-\tau_{1}+d_{c} n}{d_{c}+b_{c}}, \\
& n_{2}=\frac{\tau_{1}-\tau_{2}+b_{c} n}{d_{c}+b_{c}} .
\end{aligned}
$$

Since $n_{i} \in(0, n)$, we get $-d_{c} n<\tau_{2}-\tau_{1}<b_{c} n$.

Hence,

$$
T C_{c}=\frac{\tau_{1} d_{c}+b_{c} \tau_{2}+b_{c} d_{c} n}{d_{c}+b_{c}} n
$$

is the total time cost for common vehicles.

To find the optimal total time, the following must hold:

$$
T C_{a} \underset{m_{1}, m_{2}}{\longrightarrow} \min .
$$

The minimum of this function is reached if

$$
\begin{aligned}
& m_{1}^{0}=\frac{2 m d_{a}+\tau_{2}-\tau_{1}}{2\left(d_{a}+b_{a}\right)}, \\
& m_{2}^{0}=\frac{2 m b_{a}+\tau_{1}-\tau_{2}}{2\left(d_{a}+b_{a}\right)} .
\end{aligned}
$$

The solutions satisfy the conditions for equilibrium if $m_{1}^{0} \in(0, m)$ and $m_{2}^{0} \in(0, m)$.

Thus,

$$
-d_{a} m<\frac{\tau_{2}-\tau_{1}}{2}<b_{a} m .
$$

The system optimum for autonomous vehicles is the solution of the optimization problem

$$
T C_{a}^{0}=\frac{2 m d_{a}+\tau_{2}-\tau_{1}}{2\left(d_{a}+b_{a}\right)} \tau_{1}+b_{a} \frac{2 m d_{a}+\tau_{2}-\tau_{1}}{2\left(d_{a}+b_{a}\right)}+\frac{2 m b_{a}+\tau_{1}-\tau_{2}}{2\left(d_{a}+b_{a}\right)} \tau_{2}+d_{a} \frac{2 m b_{a}+\tau_{1}-\tau_{2}}{2\left(d_{a}+b_{a}\right)} .
$$

If $m_{1}^{0} \leqslant 0$, then all autonomous vehicles should move along the second road, hence

$$
T C_{a}^{0}=\frac{2 m d_{a}-\tau_{1}+\tau_{2}}{2\left(d_{a}+b_{a}\right)} \tau_{2}+b_{a} \frac{2 m d_{a}-\tau_{1}+\tau_{2}}{2\left(d_{a}+b_{a}\right)} .
$$


If $m_{2}^{0} \leqslant 0$, then all autonomous vehicles move along the first road, hence

$$
T C_{a}^{0}=\frac{2 m b_{a}+\tau_{1}-\tau_{2}}{2\left(d_{a}+b_{a}\right)} \tau_{2}+d_{a} \frac{2 m b_{a}-\tau_{1}+\tau_{2}}{2\left(d_{a}+b_{a}\right)} .
$$

Thus, it is possible to optimize the total time costs by setting the optimal vehicles distribution along the traffic flows. Consider four possible scenarios of arrangement of designated lanes on two roads:

1. There are designated lanes for autonomous lanes only on one road.

2. One road is available only for autonomous vehicles, while the second one has a designated lane and lanes for common vehicles.

3. One road has a fixed coefficient for a designated lane and the second road is proposed for modeling.

4. Both roads have designated lanes.

These options are the main cases of distribution of designated lanes over two roads.

\section{Option 1}

Suppose there exists a network (Fig. 2). If $\lambda_{1} \in(0,1), \lambda_{2}=0$ (road 2 has no designated lanes), then all autonomous vehicles move along the road 1 , thus

$$
\begin{gathered}
T C=T C_{0}+T C_{a}=\frac{\tau_{1} d_{c}+b_{c} \tau_{2}+d_{c} b_{c} n}{d_{c}+b_{c}} n+\left(\tau_{1}+b_{a} m\right) m, \\
d_{c}=d \quad\left(\text { since } \lambda_{2} \in(0,1)\right), \\
b_{c}=\frac{b \chi}{1-\lambda_{1}} ; \quad b_{a}=\frac{b}{\lambda_{1}} \quad\left(\text { since } \lambda_{1} \in(0,1)\right), \\
T C=(n+m) \tau_{1}+\frac{b m^{2}}{\lambda_{1}}+\frac{b n \chi\left(\tau_{2}+d n-\tau_{1}\right)}{d\left(1-\lambda_{1}\right)+b \chi} .
\end{gathered}
$$

The minimum is

$$
\lambda_{1}=\frac{m(d+b \chi)}{\sqrt{b n \chi\left(\tau_{2}+d n-\tau_{1}\right)+d m}} .
$$

Substitute (3) into (2):

$$
T C=(n+m) \tau_{1}+\frac{b m\left(\sqrt{b n \chi\left(\tau_{2}+d n-\tau_{1}\right)}+d m\right)}{(d+b \chi)}+\frac{b n \chi\left(\tau_{2}+d n-\tau_{1}\right)}{d\left(1-\frac{m(d+b \chi)}{\sqrt{b n \chi\left(\tau_{2}+d n-\tau_{1}\right)}+d m}\right)+b \chi}
$$

is the optimal value of $T C$.

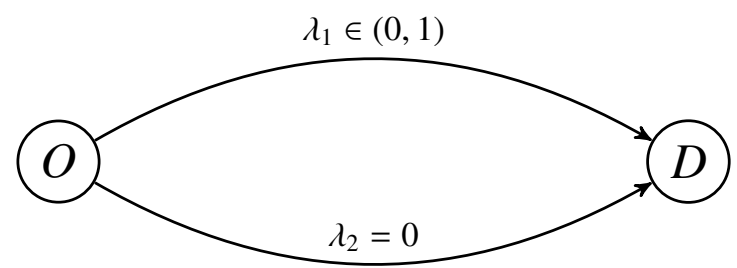

Figure 2. A network of two lines where the first lane has a $\lambda_{1}$ autonomous vehicles capacity and the second one is closed for them 
$\lambda$ is the minimum of the function (1) if $B=b n \chi\left(\tau_{2}+d n-\tau_{1}\right)>0$ and $\lambda \in(0,1)$. If $\lambda>\frac{m(d+b \chi)}{\sqrt{b n \chi\left(\tau_{2}+d n-\tau_{1}\right)}+d m}$, then $T C$ increases and if $\lambda<\frac{m(d+b \chi)}{\sqrt{b n \chi\left(\tau_{2}+d n-\tau_{1}\right)}+d m}, T C$ decreases.

\section{Option 2}

Assume that the second road is available only for autonomous vehicles (Fig.3), so $\lambda_{2}=1$ and $\lambda_{1} \in(0,1)$. This implies:

Suppose $\tau_{2}-\tau_{1}=k$.

$$
d_{a}=d ; \quad b_{c}=\frac{b \chi}{1-\lambda} ; \quad b_{a}=\frac{b}{\lambda}
$$

Thus, the minimum is achieved when

$$
m_{1}^{0}=\frac{2 m d_{a}+k}{2\left(d_{1}+b_{a}\right)} ; \quad m_{2}^{0}=\frac{2 m b_{a}-k}{2\left(d_{1}+b_{a}\right)} .
$$

So, the system optimum of $T C$ for common vehicles is

$$
T C=\frac{m\left(\tau_{1} d \lambda+\tau_{2} b+b d m\right)}{b+d \lambda}+\left(\tau_{1}+\frac{b \chi}{1-\lambda} n\right) n-\frac{k^{2} \cdot \lambda}{4(b+d \lambda)} .
$$

Hence,

$$
\lambda=\frac{-2 \sqrt{\left(\chi n^{2}\right)(b+d)^{2}(2 d m+k)^{2}}}{-4 d^{2} \chi n^{2}+4 d^{2} m^{2}+4 d k m+k^{2}}++\frac{4 b d x n^{2}+4 d^{2} m^{2}+4 d k m+k^{2}}{-4 d^{2} \chi n^{2}+4 d^{2} m^{2}+4 d k m+k^{2}} .
$$

Substitute (6) into (5):

$$
\begin{aligned}
T C & =\tau_{1} n+\frac{b \chi n^{2}\left(-(k+2 d m)^{2}+4 d^{2} \chi n^{2}\right)}{4 d(b+d) x n^{2}-2 \sqrt{(b+d)^{2} x(k+2 d m)^{2} n^{2}}}+ \\
& +\frac{k^{2}\left(-(k+2 d m)^{2}-4 b d \chi n^{2}\right)}{4(b+d)(k+2 d m)^{2}-8 d \sqrt{(b+d)^{2} \chi(k+2 d m)^{2} n^{2}}}+ \\
& +\frac{2 m(k+2 d m)^{2}\left(\tau_{1} d+b\left(\tau_{2}+d m\right)\right)}{2(b+d)(k+2 d m)^{2}-4 d \sqrt{(b+d)^{2} \chi(k+2 d m)^{2} n^{2}}}+ \\
& +\frac{-8 b d^{2} \chi m\left(-\tau_{1}+\tau_{2}+d m\right) n^{2}}{2(b+d)(k+2 d m)^{2}-4 d \sqrt{(b+d)^{2} \chi(k+2 d m)^{2} n^{2}}}+ \\
& +\frac{\left(k^{2}-4 \tau_{1} d m\right) \sqrt{(b+d)^{2} \chi(k+2 d m)^{2} n^{2}}}{2(b+d)(k+2 d m)^{2}-4 d \sqrt{(b+d)^{2} \chi(k+2 d m)^{2} n^{2}}} .
\end{aligned}
$$

Therefore, since the Pareto-optimal value of $T C$ has been found, the total traveling time may be evaluated. The total optimal traveling time for this case may be evaluated using (7).

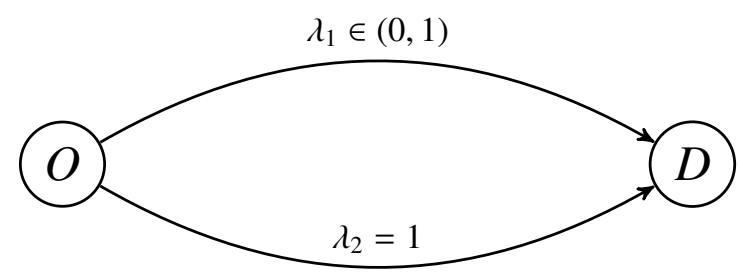

Figure 3. A network of two lines where the first lane has a $\lambda_{1}$ autonomous vehicles capacity and the second one is opened only for them 


\section{Option 3}

Consider the case where the road 2 has a fixed coefficient of designated lanes and $\lambda_{1} \in(0,1)$ (Fig. 4). This implies

$$
\begin{gathered}
d_{a}=\frac{d}{\lambda_{2}} ; \quad b_{c}=\frac{b \chi}{1-\lambda_{1}} ; \quad b_{a}=\frac{b}{\lambda_{1}} ; \quad d_{c}=\frac{b \chi}{1-\lambda_{2}}, \\
T C_{c}=\frac{\tau_{1} d \chi}{1-\lambda_{2}}+\frac{\tau_{2} b \chi}{1-\lambda_{1}}+\frac{\frac{b n d \chi^{2}}{\left(1-\lambda_{1}\right)\left(1-\lambda_{2}\right) n}}{\frac{d \chi}{1-\lambda_{2}}+\frac{b \chi}{1-\lambda_{1}}} n \\
T C_{a}^{0}=\frac{m}{\left(\frac{d}{\lambda_{2}}+\frac{b}{\lambda_{1}}\right)}\left[\tau_{1} \frac{d}{\lambda_{2}}+\tau_{2} \frac{b}{\lambda_{1}}+\frac{d b}{\lambda_{2} \lambda_{1}} m\right]-\frac{\left(\tau_{2}-\tau_{1}\right)^{2}}{4\left(\frac{b}{\lambda_{1}}+\frac{d}{\lambda_{2}}\right)} .
\end{gathered}
$$

The minimum of the $T C=T C_{c}+T C_{a}$ is reached at the point

$$
\lambda_{1}=\frac{\sqrt{C}\left(\frac{b}{d}\left(1-\lambda_{2}\right)+1\right)-\sqrt{B} \frac{b \lambda_{2}}{d}}{\sqrt{B}+\sqrt{C}},
$$

where

$$
\begin{aligned}
& A=\left(\tau_{1} n+\frac{m\left(4 \tau_{1} d-\left(\tau_{2}-\tau_{1}\right)^{2} \lambda_{2}\right)}{4 d}\right), \\
& B=n\left(\frac{b\left(1-\lambda_{2}\right)}{d}\left(\tau_{2}-\tau_{1}\right)+b \chi n\right), \\
& C=\frac{m b}{d}\left(\left(\tau_{2} \lambda_{2}+d m\right)-\frac{\lambda_{2}\left(4 \tau_{1} d-\left(\tau_{2}-\tau_{1}\right)^{2} \lambda_{2}\right)}{4 d}\right) .
\end{aligned}
$$

However, the constraints imposed on $\lambda \in(0,1)$ can provide the boundary solutions described in Options 1 and 2.

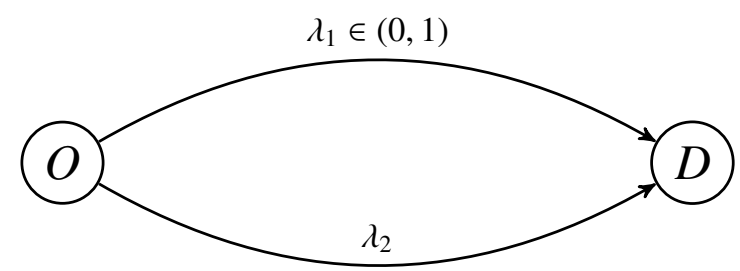

Figure 4. A network of two lines where the first lane has a $\lambda_{1}$ autonomous vehicles capacity and autonomous vehicles capacity coefficient for the second road $\lambda_{2}$ is fixed

\section{Option 4}

Consider the case where the autonomous vehicles can move along both roads and the coefficient for each road is not fixed, $\lambda_{1} \in(0,1), \lambda_{2} \in(0,1)$ (Fig. 5). In this case we have to find the extrema of the function of two variables: $\lambda_{1}, \lambda_{2}$. This leads us to the search for two separate extrema as functions 


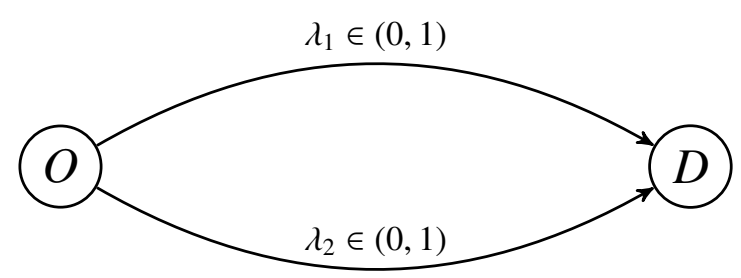

Figure 5. A network of two lines where $\lambda_{i}$ is an $i$ th lane's autonomous vehicles capacity coefficient

of $\lambda_{i}$ from $\lambda_{j}, i, j=1,2$, based on the results obtained in Option 3. However, the boundary solutions have more complex structure in this case.

$$
\begin{aligned}
T C & =T C_{c}+T C_{a}^{0}= \\
& =\frac{\tau_{1} d\left(1-\lambda_{1}\right)-b \tau_{2}\left(1-\lambda_{2}\right)+b d \chi n}{b\left(1-\lambda_{2}\right)+d\left(1-\lambda_{1}\right)} n+\frac{m}{\left(d \lambda_{1}+b \lambda_{2}\right)} \times \\
& \times\left(\left[\tau_{1} d \lambda_{1}+\tau_{2} b \lambda_{2}+d b m\right]-\frac{1}{4}\left(\tau_{1}-\tau_{2}\right)^{2} \lambda_{1} \lambda_{2}\right) .
\end{aligned}
$$

Suppose $k=\tau_{2}-\tau_{1}$.

Thus,

$$
\left\{\begin{array}{l}
\lambda_{1}=\frac{(b+d)\left(2 m b+k \lambda_{2}\right)}{b\left(2 m b+k \lambda_{2}+2 \sqrt{\psi}\right)}-\frac{d \lambda_{2}}{b}, \\
\lambda_{2}=\frac{(b+d)\left(2 m b+k \lambda_{1}\right)}{b\left(2 m b+k \lambda_{1}+2 \sqrt{\xi}\right)}-\frac{d \lambda_{1}}{b},
\end{array}\right.
$$

where $\psi=n b\left(k\left(1-\lambda_{2}\right)+b n \chi\right), \xi=n b\left(k\left(1-\lambda_{1}\right)+b n \chi\right)$.

The solution of (10) can be found using a computer environment with further substitution of the resulting values into equation (9). Equation (9) implies that $\lambda_{1}$ and $\lambda_{2}$ exist only if:

$$
\begin{cases}n d\left(k\left(1-\lambda_{2}\right)+d n \chi\right) & \geqslant 0 \\ n b\left(k\left(1-\lambda_{1}\right)+b n \chi\right) & \geqslant 0 \\ \frac{d n \chi}{k}-1 & \geqslant \lambda_{2} ; \\ \frac{b n \chi}{k}-1 & \\ \lambda_{1} \in(0,1), \quad \lambda_{2} \in(0,1) . & \end{cases}
$$

If (10) has no solutions on the interval $(0,1)$, then the optimal values are not in the domain. Therefore, consider $\lambda_{1}, \lambda_{2} \in\{0,1\}$, where $\lambda_{i}=0$ corresponds to the road without designated lanes and $\lambda_{i}=1$ corresponds to the road available only for autonomous vehicle. Hereby, all special cases of designating lanes on two roads were considered.

\section{Model description on Braess' network}

Consider the simple Braess network (Fig. 6). Let $N_{a}, N_{c}$ be the total number of autonomous and common vehicles, respectively.

Thus, the total number of autonomous and common vehicles on each of the five roads is equal to

$$
n^{1}=N^{1}+N^{3}, \quad n^{2}=N^{1}, \quad n^{3}=N^{2}, \quad n^{4}=N^{2}+N^{3}, \quad n^{5}=N^{3} .
$$




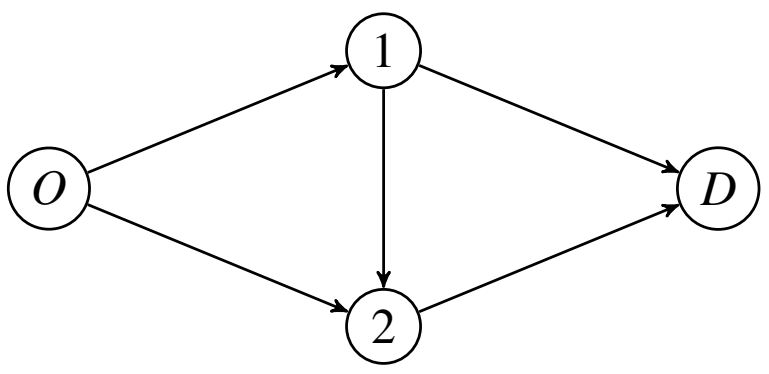

Figure 6. An example of a simple Braess network

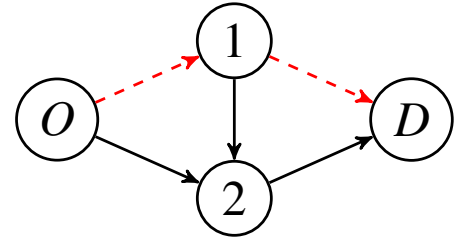

Figure 7. 1st network traversal option

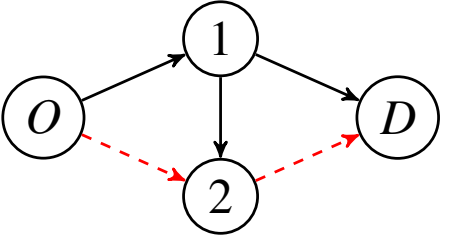

Figure 8. 2nd network traversal option

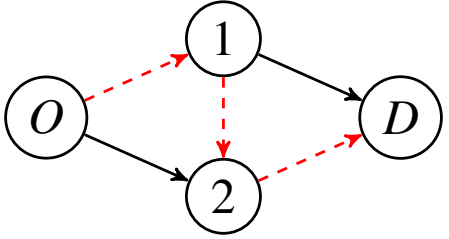

Figure 9. 3rd network traversal option

Using the results obtained from Options 1,2,3, and 4, TC for each route can be evaluated. At the same time computational modeling allows evaluation of possible delays in general form.

\section{Algorithm}

We propose the following algorithm:

1. Fix the set of lambda.

2. Look for the social optimum for the autonomous vehicles. It will reach the minimum $T C_{a}$ on the set $N_{a}$ on 3 trajectories.

$$
T C_{a}=\left(t_{a}^{1}+t_{a}^{2}\right) N_{a}^{1}+\left(t_{a}^{1}+t_{a}^{4}+t_{a}^{5}\right) N_{a}^{3}+\left(t_{a}^{3}+t_{a}^{4}\right) N_{a}^{2} .
$$

3. Look for the user equilibrium for the common vehicles. Choose the quant of size $Q$ which is a small part of a virtual vehicle.

4. Set $W$ as a number of common vehicles. There will be $W \cdot Q$ of quants in queue.

5. Extract the next quant from queue and find the best route for it. Repeat until the queue becomes empty. Add the quant size to route counters.

6. $T C_{c}$ is calculated from the values of the route counters.

7. Find $T C=T C_{a}+T C_{c}$. Repeat step 1 to step 6 to find the minimum $T C$.

The algorithm (page 290) iterates through the possible combinations of edges and distribution of designated lanes on them, calculating the smallest value of TC and the corresponding value $\lambda$. According to the principle of greedy behavior, each driver chooses the optimal route in terms of the total traveling time. This forms Wardrop equilibrium and the system optimum is reached. The algorithm (page 290) was realized in $C++$ programming language. 


\section{Results of modeling}

\section{Only common vehicles}

Assume that we have only common vehicles on all routes. At first compute $T C$ and the equilibrium on traffic flows. Fix the parameters of the Braess paradox network which were proposed in [Steinberg, 1983] (Fig. 10) and increase the value of the lanes coefficient $\lambda$ for autonomous vehicles on edge $A-B$.

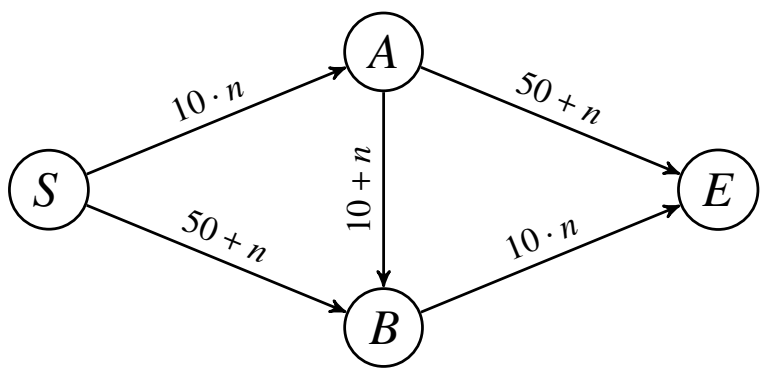

Figure 10. An example of Braess' network that was used for testing our numerical model

From the results shown in the chart $T C(\lambda)$ (Fig. 11) it can be concluded that the optimal solution is reached if the road $A-B$ is available only for autonomous vehicles. The same results were obtained in [Steinberg, 1983], which proves the correctness of the developed program and the applied algorithm.

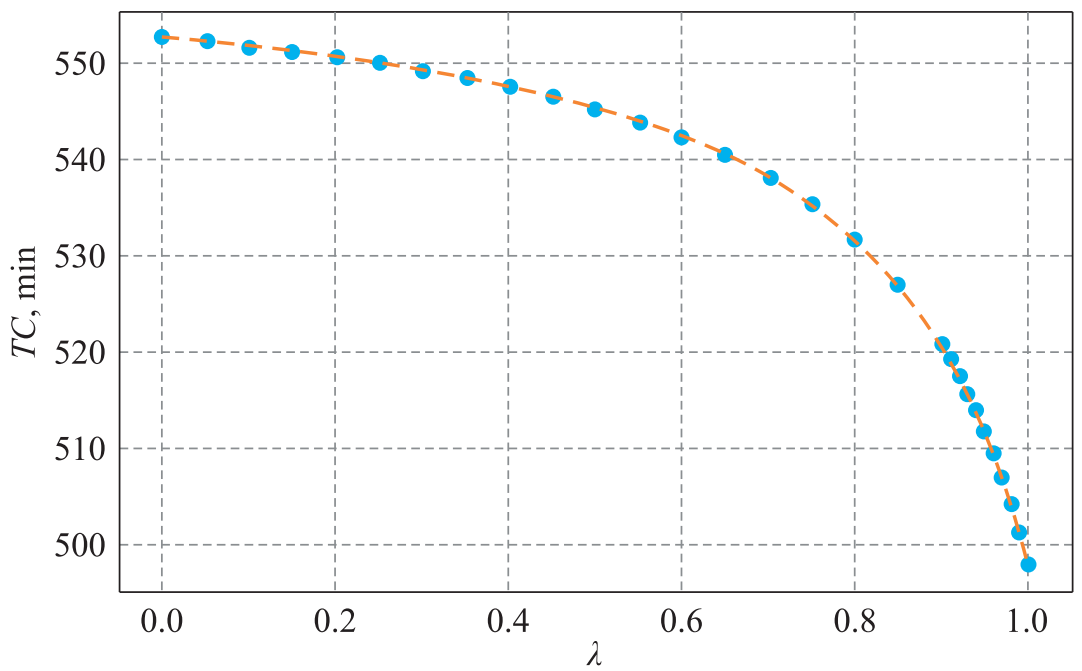

Figure 11. Relation between $T C$ and $\lambda$ graph

\section{Autonomous and common vehicles}

Consider the traffic flows in the same transportation network and explore the dependence of the optimal total time on the efficiency coefficient $\chi$. If we fix the parameter $\lambda$ and increase parameter $\chi$, we get the results of the algorithm [Steinberg, 1983] (page 290) which are demonstrated on the following chart $T C(\chi)$.

This chart (Fig. 12) shows the linear dependence, which implies that there should be no common vehicles on route 3 (Fig. 9), nor on route $A-B$. In the case of Braess' paradox in the model with common vehicles, the only solution is to make the road $A-B$ available only for autonomous vehicles. 


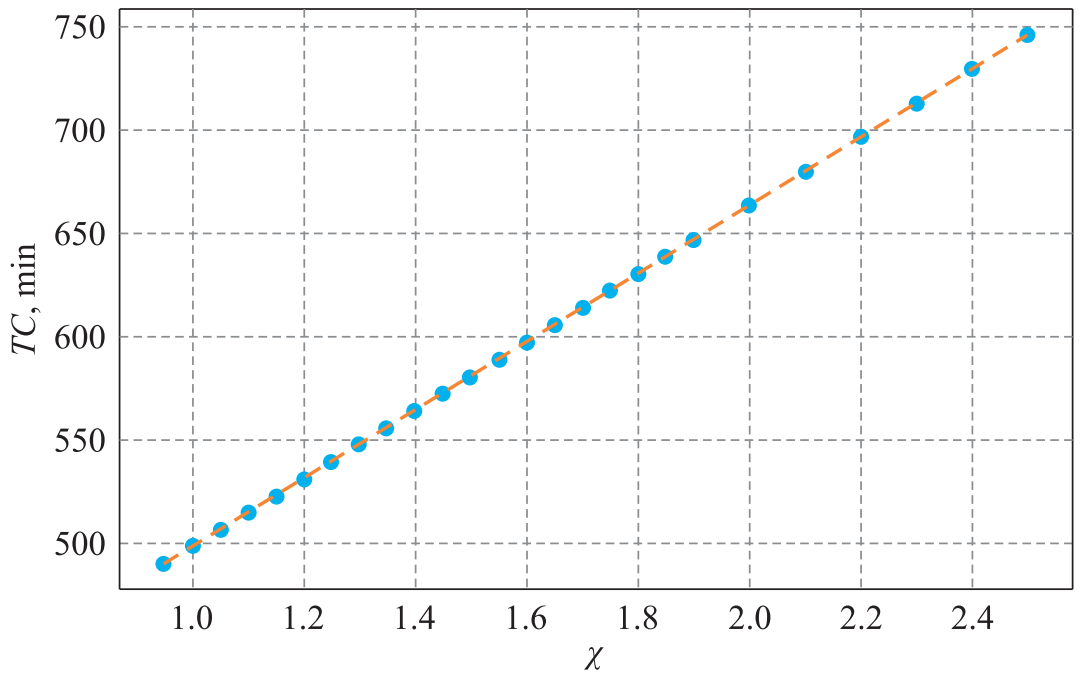

Figure 12. Relation between $T C$ and $\chi$ graph

\section{Examples of real-life network modeling}

It is not a rare scenario when Braess' paradox occurs after some time when the amount of traffic on the network reaches a certain value. The simplest way to deal with it is to remove the "problematic" edge from the network. In this article an alternative solution is proposed. This solution involves the traffic flow adjustment method, which is based on the principle of addition of designated lanes. Consider an example of an isolated network in one of Moscow districts (Fig. 13).

There are two possible ways to get to VDNKh when the vehicle moves along the Schyolkovskoye highway (Fig. 13). The first trajectory is along Third Ring Rd and then along Prospekt Mira (white trajectory) or along Rostokinsky proezd (red trajectory). The black route is faster, since it takes

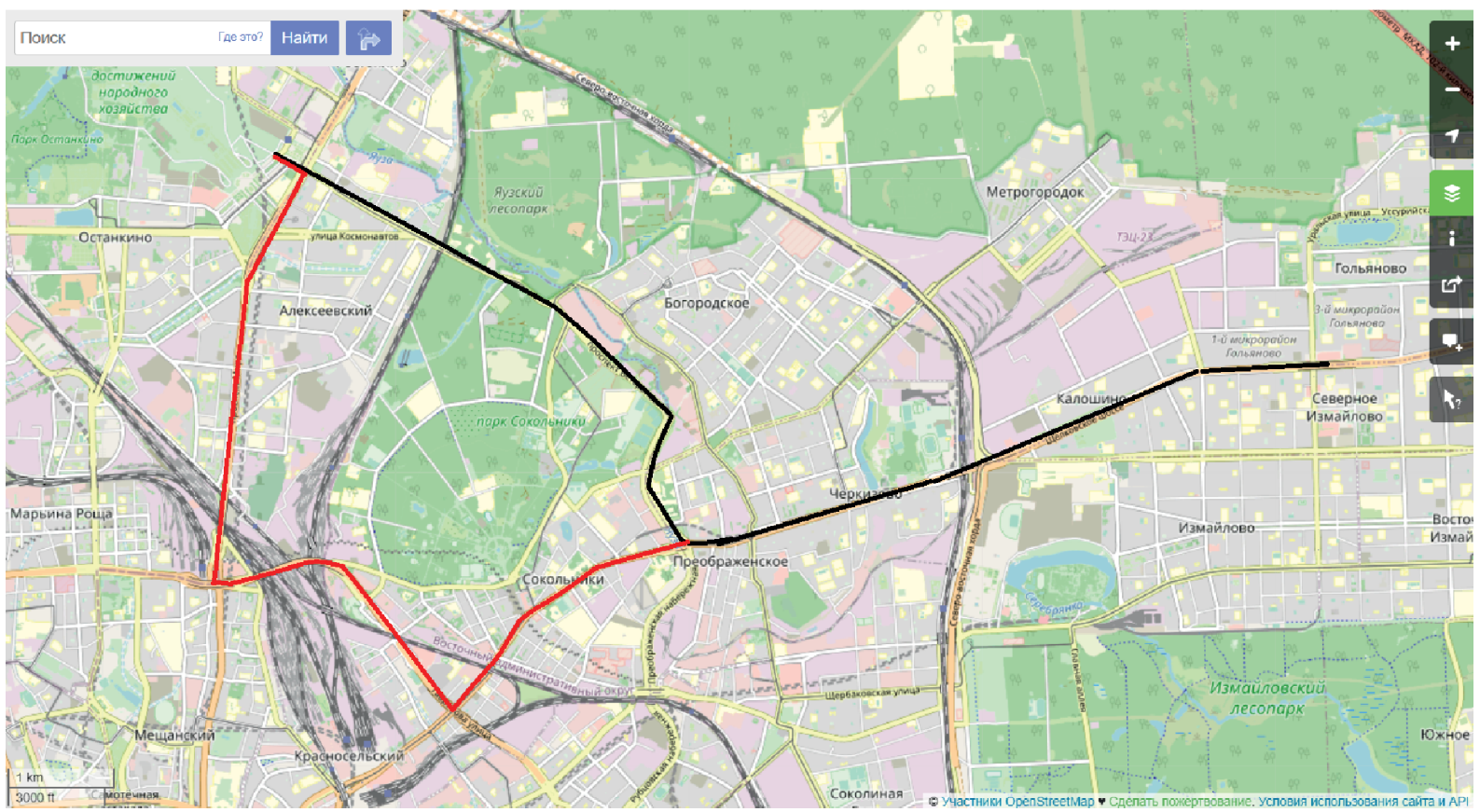

Figure 13. Map used for modeling, [OpenStreetMap, CODD, Otraslevoy...] 
16 minutes to get from the starting point (red) to the end point (blue) without traffic jams. The white toute takes 23 minutes without traffic jams. However, the white route has greater capacity (4 lanes may serve up to 8300 vehicles per hour), while the black route has only 2 lanes and a capacity of 6700 vehicles per hour.

Since Rostokinsky proezd is located near Bogorodskoye and Metrogorodok districts, increasingly more drivers from these districts choose the black route. In order to save time, the driver would rather choose Rostokinsky proezd. When the number of vehicles on this route is large, the traffic will be backed up. This is the situation when Braess' paradox occurs. If there were no route Schyolkovskoye highway - Veteranov Avenue - Rostokinsky proezd, the traffic on this road system would be more optimal. Perform analysis for this network. Consider the graph of the network.

There are two possible trajectories. The capacity of the route through Metrogorodok is 6700 vehicles per hour and through TRR - 8300 vehicles per hour. If the traffic through Rostokinsky proezd is restricted for drivers from Schyolkovskoye highway, the total system load decreases. To solve the paradox, we can delete the Schyolkovskoye highway - Metrogorodok edge from the network. Consider an example. Assume that there are 7000 vehicles. 5000 vehicles move along the Schyolkovskoye highway and have to choose the trajectory and the remaining 2000 vehicles are in Metrogorodok. Suppose that 2000 vehicles choose Rostokinsky proezd and 3000 choose TRR (the data was obtained during observation from 7 to 8 am during rush hours).

Let the total time cost on the road segment $i$, where $i \in\{1,2\}$ is the set of trajectories, be a linear function $t_{i}=\tau_{i}+b_{i} n_{i}$, where for routes 1 and $2 b_{1}=\frac{60}{6700}=0.009, b_{2}=\frac{60}{8300}=0.007$, respectively. Thus, $T=t_{1}+t_{2}=\tau_{1}+b_{1} n_{1}+\tau_{2}+b_{2} n_{2}=96 \mathrm{~min}$ is the total traveling time through both trajectories. The average time is $48 \mathrm{~min}$.

Now consider the case where there is no edge which connects the Schyolkovskoye highway and Metrogorodok. Then $n_{1}=2000, n_{2}=5000$. Thus $T=t_{1}+t_{2}=\tau_{1}+b_{1} n_{1}+\tau_{2}+b_{2} n_{2}=92 \mathrm{~min}$. The average time is $46 \mathrm{~min}$.

Therefore, this implies that the removal of this edge from the network optimizes the total network load.

Now consider the modeling on this transportation network. According to gucodd.ru, in Moscow, public transport accounts for $2 \%$ of the total amount of vehicles. Thus, if we have 7000 vehicles in total, 140 of them are public. According to the efficiency coefficient, $\chi=0.7$, which implies that the public transport traffic is less effective. Since $\lambda_{1} \in(0,1), \lambda_{2}=0$ by definition, all public vehicles will move along the first road. Therefore,

$$
T C=(n+m) \tau_{1}+\frac{b m\left(\sqrt{b n \chi\left(\tau_{2}+d n-\tau_{1}\right)}+d m\right)}{(d+b \chi)}+\frac{b n \chi\left(\tau_{2}+d n-\tau_{1}\right)}{d\left(1-\frac{m(d+b \chi)}{\sqrt{b n \chi\left(\tau_{2}+d n-\tau_{1}\right)}+d m}\right)+b \chi}
$$

is the optimal value of $T C$ for this system (5).

Therefore, the total time cost is

$$
T C=112000+\frac{62.72}{0.0133}+\frac{2377.9}{0.013}=299631 .
$$

By evaluating the average traveling time for both trajectories in this network for a common vehicle, we get

$$
t_{1,2}=\frac{299631}{7000}=42.8 \mathrm{~min} .
$$

Hence, the proposed method allows to reduction of the network load. 


\section{Conclusion}

In this article the problem of network system modeling has been solved using a set of examples. It was shown that Braess' paradox can significantly amplify the total network load. The model of designated lanes was proposed. Simple cases of organizing designated lanes were considered. Optimal strategies for common and autonomous vehicles were obtained. The model realization was illustrated by an example. It was found that the modeling of designated lanes eliminates Braess' paradox and optimizes the total traveling time. The algorithm which simulates drivers' behavior to determine the system equilibrium was proposed and realized in programming language.

\section{Список литературы (References)}

Beckmann M.J., McGuire C.B., Winsten C.B. Studies in the Economics of Transportation. - Rand Corporation, 1955.

Braess D., Nagurney A., Wakolbinger T. On a paradox of traffic planning // Transportation science. 2005. - Vol. 39, No. 4. - P. 446-450.

CODD [Electronic resource]. - URL: http://www.gucodd.ru (accessed: 29.04.2021).

Daganzo C.F. A behavioral theory of multi-lane traffic flow. Part I: Long homogeneous freeway sections // Transportation Research Part B: Methodological. - 2002. - Vol. 36, No. 2. P. $131-158$.

Fisk C.S. Game theory and transportation systems modelling // Transportation Research Part B: Methodological. - 1984. - Vol. 18, No. 4-5. - P. 301-313.

Kerner B. S., Klenov S. L. Probabilistic breakdown phenomenon at on-ramp bottlenecks in three-phase traffic theory // Transportation research record. - 2006. - Vol. 1965, No. 1. - P. 76-78.

Kiesling M., Ridgway M. Effective bus-only lanes // ITE JOURNAL. - 2006. - Vol. 76, No. 7. P. 24.

Milchtaich I. Network topology and the efficiency of equilibrium // Games and Economic Behavior. 2006. - Vol. 57, No. 2. - P. 321-346.

Nesterov Y., De Palma A. Stationary dynamic solutions in congested transportation networks: summary and perspectives // Networks and spatial economics. - 2003. - Vol. 3, No. 3. - P. 371-395.

OpenStreetMap [Electronic resource]. - URL: https://openstreetmap.org/ (accessed: 29.04.2021).

Otraslevoy dorozhniy metodicheskiy document [Industry road guidance document] [Electronic resource]. - URL: https://docs.cntd.ru/document/1200092512 (accessed: 29.04.2021) (in Russian).

Amaral R., Aghezzaf E.-H. The Downs-Thompson paradox in multimodal networks // 2nd International Conference on Traffic and Transport Engineering (ICTTE). - 2014. - P. 76-85.

Roughgarden T. On the severity of Braess's paradox: designing networks for selfish users is hard // Journal of Computer and System Sciences. - 2006. - Vol. 72, No. 5. - P. 922-953.

Steinberg R., Zangwill W. I. The prevalence of Braess' paradox // Transportation Science. - 1983. Vol. 17, No. 3. - P. 301-318.

Thorns D.C. The transformation of cities: urban theory and urban life // Macmillan International Higher Education, 2017.

Valiant G., Roughgarden T. Braess's paradox in large random graphs // Random Structures \& Algorithms. - 2010. - Vol. 37, No. 4. - P. 495-515.

Wardrop J.G., Whitehead J.I. Correspondence. some theoretical aspects of road traffic research // Proceedings of the Institution of Civil Engineers. - 1952. - Vol. 1, No. 5. - P. 325-378. 